\title{
Measuring the equity of inpatient utilization in Chinese rural areas
}

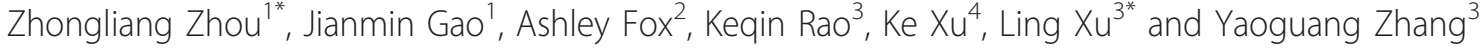

\begin{abstract}
Background: As an important outcome of the health system, equity in health service utilization has attracted an increasing amount of attention in the literature on health reform in China in recent years. The poor, who frequently require more services, are often the least able to pay, while the wealthy utilize disproportionately more services although they have less need. Whereas equity in health service utilization between richer and poorer populations has been studied in urban areas, the equity in health service utilization in rural areas has received little attention. With improving levels of economic development, the introduction of health insurance and increasing costs of health services, health service utilization patterns have changed dramatically in rural areas in recent years. However, previous studies have shown neither the extent of utilization inequity, nor which factors are associated with utilization inequity in rural China.
\end{abstract}

Methods: This paper uses previously unavailable country-wide data and focuses on income-related inequity of inpatient utilization and its determinants in Chinese rural areas. The data for this study come from the Chinese National Health Services Surveys (NHSS) conducted in 2003 and 2008. To measure the level of inequity in inpatient utilization over time, the concentration index, decomposition of the concentration index, and decomposition of change in the concentration index are employed.

Results: This study finds that even with the same need for inpatient services, richer individuals utilize more inpatient services than poorer individuals. Income is the principal determinant of this pro-rich inpatient utilization inequity- wealthier individuals are able to pay for more services and therefore use more services regardless of need. However, rising income and increased health insurance coverage have reduced the inequity in inpatient utilization in spite of increasing inpatient prices.

Conclusions: There remains a strong pro-rich inequity of inpatient utilization in rural China. However, a narrowing income gap between the rich and poor and greater access to health insurance has effectively reduced income inequality, equalizing access to care. This suggests that the most effective way to reduce the inequity is to narrow the gap of income between the rich and poor while adopting social risk protection.

\section{Background}

As an important outcome of health system, equity in health service utilization has attracted an increasing amount of attention in China in recent years [1-3]. Researchers frequently distinguish between incomerelated inequalities and income-related inequities. Income-related inequality in health utilization refers to the disparities in utilization of health services between

\footnotetext{
* Correspondence: zzliang1981@163.com; xuling@moh.gov.cn

${ }^{1}$ School of Public Policy and Administration, Xi'an Jiaotong University, Xi'an, China

${ }^{3}$ Centre of Health Statistics and Information, Ministry of Health, Beijing, China Full list of author information is available at the end of the article
}

different income groups. For an inequality to be interpretable as an inequity, differential need must be taken to into account [4]. A common interpretation of equity in health utilization is that health care ought to be allocated on the basis of health need, rather than on the basis of demographic characteristics such as, income, race, or area of residence [5]. Health services are equitably distributed and utilized when people who have greater need use health services proportionally more than those with less need. The conceptual literature on equity in health utilization distinguishes between horizontal and vertical equity. Horizontal equity is interpreted to mean that persons in equal need of care ought, on average, to be

\section{Ciomed Central}


treated the same, irrespective of their socioeconomic status [6]. Vertical equity is the unequal, but equitable, treatment of individuals in unequal levels of need [7]. Because analysis of vertical inequity is problematic the economic literature, much of the empirical work in this area has focused on horizontal equity. If an equitable system is one that would allocate more resources towards the neediest segments of society, then poor, rural residents should receive more services in proportion to their need.

As a rapidly industrializing middle income country, the widening income-related inequity in access to health services among residents has been a growing concern of the Chinese government. Whereas the equity in health service utilization in urban settings has received a great deal of attention, far less attention has been paid to health services equity in rural areas. Yet, in spite of large amounts of internal migration, China remains a largely rural country. With more than $50 \%$ of people living in rural areas [8], the equity in health service utilization of rural residents is of increasing concern to China's national equity in health service utilization. Further, in spite of economic growth over the last thirty years, large income gaps between urban and rural residents remain. The per capita income for rural residents is less than one third of urban residents [8]. Whereas extreme poverty is on the decline in urban areas, continued high levels of entrenched poverty make rural residents more vulnerable to an array of diseases. With wide gaps between rich and poor in rural areas, increasing health service utilization may be more urgent for poor rural residents than for poor urban residents as a means of improving health status and reducing health inequities.

Furthermore, among rural residents, the inequality of inpatient utilization is even higher than the inequality of outpatient utilization. Poorer individuals use disproportionately fewer in-patient services, which tend to be more costly, compared with wealthier individuals. For instance, when all residents are divided into five equal groups after being ranked by income, the annual hospitalization rates for the richest rural people is $14.3 \%$ more than that for the poorest people, while the same number of outpatient rates for two weeks is only $1.4 \%$ [9] though little is understood about why this is the case. Previous studies have found that low income is the main reason that prevents the poor from having access to hospitalization $[10,11]$. Thus, compared with outpatient utilization, the inequality of inpatient utilization requires greater attention. For these reasons, the Chinese government implemented the New Cooperative Medical Scheme (NCMS) for rural residents in 2004. NCMS is a community-based rural health insurance scheme that incorporates two important policy features: voluntary enrollment and coverage of catastrophic illnesses. With the objectives of protecting households from medical impoverishment and improving the equity of inpatient utilization, the target of NCMS is to protect against "catastrophic" inpatient expenses, under the rationale that most households generally are able to afford expenses of minor illness. Thus, although NCMS should have little impact on equalizing routine outpatient visits, the plan should have a substantial equalizing effect on inpatient visits.

Previous studies have indicated that income level, the growth of medical price and medical expenditure payment methods are three main determinants that influence Chinese health service utilization $[12,13]$. Rising income levels, decreasing medical prices and the implementation of health insurance are factors that should increase health service utilization. Over the past decade, these factors have changed a great deal in rural China. From 2000 to 2009, China experienced rapid economic growth, leading to improved income for a large number of citizens. With an average annual growth rate of rural residents' income of $9.6 \%$, the benefits of economic growth have not been limited to urban areas $[8,14]$. However, whereas improved income should increase rural residents' ability to pay, the rising cost of care in rural areas may offset the benefits of socioeconomic development. For instance, the inpatient cost of health services for Chinese rural residents has been rising at an alarming rate with an average growth rate of $7.0 \%$ from 2000 to $2009[15,16]$. Increasing coverage of health insurance should off-set these rising health care costs to some degree. Yet, in 2000 less than 20\% of rural residents were covered by a health insurance scheme [17]. In order to make up for this rising cost of care, and to pool risk more equitably, in 2004, the national government implemented the New Cooperative Medical Scheme, which has covered $94 \%$ of rural residents as of 2009 [16]. While insurance should theoretically equalize access to health services across income groups by removing ability to pay as a barrier to care, equality of access may not always translate directly into equality of utilization. Other barriers to access such as distance to health clinics, lack of transportation or preferences for traditional medicine may also affect income-related inequalities in health service utilization. Given these changes in the determinants of health service utilization in rural areas over the last decade, studies are needed on how these developments have affected the inequality of inpatient utilization in rural China and whether the remaining inequality is inequitable. If inpatient utilization differs between different income groups, but these differences are proportional to need, then these differences are not inequitable. If, on the other hand, health service utilization is lower among 
those who require proportionally more or the same amount of services, this inequality can indeed be considered inequitable. The concentration index is a means of measuring the level of inequity of health services that allows various components of inequality to be decomposed.

Because country-wide data has until recently been unavailable, previous studies have shown neither the full extent of inpatient utilization inequity nor by how much various determinants contribute to inequity in rural areas $[18,19]$. Furthermore, with only aggregated regional data available, most studies have focused on income-related inequality- whether there are income differences in utilization rates- rather than income-related inequity based on need $[20,21]$. The study of equity in inpatient utilization for Chinese rural residents using country-wide data goes beyond previous studies to examine the inequity of utilization rates across all rural areas over time.

The purpose of this study is to analyze the present degree of horizontal equity in Chinese rural residents' inpatient utilization, the contributions of the primary determinants of utilization to level of equity and the contributions of determinants to the increasing or decreasing equity from 2003 to 2008 . These findings can be used to make recommendations on how to improve the equity of health utilization for rural residents in rapidly developing countries.

\section{Methods}

\section{Data}

The data utilized in this study are from China's National Health Services Surveys completed in 2003 and 2008. These surveys, organized and directed by the Centre for Health Statistics and Information of the Chinese Ministry of Health, were conducted in China for both urban and rural areas in 1993, 1998, 2003 and 2008. This paper uses only the data generated from household questionnaire interviews carried out among the rural residents. The surveys include variables on demographics, income variables, health status, medical service utilization and medical expenses.

A four-stage stratified random sampling procedure and method was used in the household survey in order to achieve maximum representation of the demographic and socio-economic characteristics of the whole population. In the first stage, all the counties in the rural area were grouped into 5 groups according to 10 socio-economic indicators and counties were selected randomly in each group: 67 in 2003 and 64 in 2008. In the second stage, five townships in each county were randomly chosen. In the third stage, two villages in each township were selected. Finally, 60 households were identified in each village. The total number of rural households sampled in 2003 and 2008 were 143,991 and 129,301 respectively. Only the people who were 15 years old and older were selected in this study and the sample sizes are 112,116 in 2003 and 103,754 in 2008.

\section{Methods to measure health utilization inequality and inequity}

The concentration index $(\mathrm{CI})$ is employed in this paper to measure health utilization inequality. The concentration index, which quantifies the degree of income-related inequality in a health variable [22,23], is becoming a standard tool for the measurement of income-related health inequality [24]. The concentration index is zero if there is no income-related inequality of health utilization. If the concentration index takes on a positive (negative) value, there is a pro-rich (pro-poor) inequality in inpatient utilization. The general formula for the concentration index defines it in terms of the covariance between the health variable and the fractional rank in the income distribution [25].

$$
C=\frac{2}{\mu} \operatorname{cov}(y, r)
$$

Where $C$ is concentration index; $y$ is inpatient utilization index; $\mu$ is the mean of inpatient utilization index and $r$ is the fractional rank in the income distribution.

The method of decomposition of the concentration index is used to analyze the contributions of various determinants of utilization to the inequality in inpatient utilization and to calculate horizontal inequity. Decomposition of the concentration index, proposed by Wagstaff [26], is a straightforward way to decompose the measured degree of inequality into the contributions of various explanatory factors. According to this method, the concentration index of inpatient utilization can be decomposed into contributions of determinants to income-related inequality using the method of decomposition of concentration index [26]. In keeping with previous studies, the inequality of inpatient utilization is decomposed into four components in this paper [4]: (1) the contribution of individual income; (2) the contribution of the need variables; (3) the contribution of other explanatory variables (i.e., inpatient price); (4) the contribution of the residual term which captures the degree to which the residual is correlated with income rank. In order to decompose the inequality of inpatient utilization, a regression model should be given by

$$
y_{i}=\alpha+\beta_{m} x^{m}+\sum_{n} \beta_{n} x_{i}^{n}+\sum_{p} \beta_{p} x_{i}^{p}+\varepsilon_{i}
$$

Where $y_{i}$ is inpatient utilization; $x^{m}$ is income; $x^{n}$ are need variables; $x^{p}$ are other variables; $\beta_{m}, \beta_{n}$ and $\beta_{p}$ are coefficients; $\varepsilon_{i}$ is the implied error term, which includes approximation errors. Then the concentration index for $y$ can be written as 


$$
\begin{aligned}
& \hat{C}=\left(\beta_{m} \bar{x}_{m} / \bar{y}\right) \hat{C}_{m}+\sum_{n}\left(\beta_{n} \bar{x}_{n} / \bar{y}\right) \hat{C}_{n} \\
& +\sum_{p}\left(\beta_{p} \bar{x}_{p} / \bar{y}\right) \hat{C}_{p}+G C_{\varepsilon} / \bar{y}
\end{aligned}
$$

Where $\hat{C}$ is the concentration index of inpatient utilization, and $\hat{C}_{m}, \hat{C}_{n}$ and $\hat{C}_{p}$ are the concentration indexes of $x^{m}, x^{n}$ and $x^{p}$. The first term of the right side of equation 3 denotes the contribution of income to inequality, the second denotes the contributions of need variables, the third denotes the contributions of other variables and the last term is the generalized concentration index of $\varepsilon_{i}$. The horizontal inequity (HI) of inpatient utilization can be computed by subtracting the contribution of need variables from the concentration index of inpatient utilization [26].

In order to explain changes in income-related inequality in health service utilization over time, the method of decomposition of change in concentration index, as proposed by Wagstaff [26], is used to decompose the change of concentration index in inpatient utilization from 2003 to 2008. The change of concentration index was further decomposed to assess the contributions of different determinants of health service utilization (see equation 4).

$$
\begin{aligned}
& d C=-\frac{C}{\bar{y}} d \alpha+\sum_{k} \frac{\bar{x}_{k}}{\bar{y}}\left(C_{k}-C\right) d \beta_{k}+\sum_{k} \frac{\beta_{k}}{\bar{y}}\left(C_{k}-C\right) d \bar{x}_{k} \\
& +\sum_{k} \frac{\beta_{k} \bar{x}_{k}}{\bar{y}} d C_{k}+d \frac{G C_{\varepsilon}}{\bar{y}}
\end{aligned}
$$

Note that the effect on $C$ of a change in $\beta_{k}$, or in $\bar{x}_{k}$, depends on whether $x_{k}$ is more unequally or less unequally distributed than $y$. This reflects two separate channels of influence-the direct effect of the change in $\beta_{k}$ (or $\left.\bar{x}_{k}\right)$ on $C$ and the indirect effect operating through $\bar{y}$.

\section{Regression models}

Two non-linear regression models are employed to decompose the concentration index and to decompose the change of concentration index. Probit regression models are used to analyze the influences of determinants on the probability of an inpatient visit, generalized negative binominal regression models are used to analyze the influences of various determinants of utilization on number of inpatient visits and zero-truncated negative binomial regression models are used to analyze the influences of determinants on per-visit hospitalization days. The linear approximation to the non-linear model is made to estimate the marginal effects evaluated at the means in the process of decomposing concentration index [5].

\section{Variables}

\section{(a)Inpatient utilization}

In keeping with previous studies on inpatient utilization in China, inpatient utilization is measured in three separate ways: 1 . The probability of making an annual inpatient visit; 2 . The number of annual inpatient visits; and 3. Pervisit hospitalization days. The probability of an annual inpatient visit refers to the probability of initial use of an inpatient visit in the previous year. Inpatient visits refers to the total number of visits per person per year (including the initial use of inpatient visits and subsequent visits). Per-visit hospitalization days capture the number of hospital days for each episode of hospitalization.

\section{(b)Independent variables}

In order to be consistent with the method of decomposing the concentration index, independent variables in the regression model are classified into three groups: income, need variables and other variables. Income is measured by self-reported consumption expenditure. Consumption expenditure is used rather than self-reported income because income is more likely to be misreported and consumption expenditure is a better proxy for resources available $[27,28]$. The contribution of income is defined as the product of the income elasticity in inpatient visits and the concentration index of income. Need is an elusive concept that has been given a variety of interpretations in relation to the definition of equity in health care delivery $[29,30]$. Here need variables include sex, age and health status. Health status is self-reported by residents, which includes illness in the last two weeks, chronic disease, sick days in last two weeks, days of staying in bed in last two weeks, days off work and study in last two weeks, and a health status index. In 2003, the residents' health status index was divided into five categories: excellent health, good health, average health, poor health, very poor health, while the health status index was measured by scores (ranged from 0 to 100) in 2008.

Other variables include marital status, educational level, occupations, regions, health insurance schemes, time to go to the nearest medical institution, outpatient price and inpatient price. In addition to these standard control variables, we introduce more detailed variables regarding health insurance schemes, outpatient price and inpatient price. In rural China, Cooperative Medical Scheme (CMS) and New Cooperative Medical Scheme (NCMS) (both community-based health insurance schemes) were the main health care insurances for rural people in the year of 2003 and 2008, respectively. In addition, in this paper, outpatient price and inpatient price are measured by the medians of per-visit outpatient expenses and per-visit inpatient expenses at the county level in rural areas.

\section{Results}

\section{Descriptive analysis}

Table 1 shows that, from 2003 to 2008, the probability of an inpatient visit and the number of inpatient visits of Chinese rural residents increased greatly, with growth 
Table 1 Description of variables in the year of 2003 and 2008 (Percentage/means)

\begin{tabular}{|c|c|c|c|}
\hline Variable & Description & 2003 & 2008 \\
\hline \multicolumn{4}{|l|}{ Inpatient utilization } \\
\hline $\begin{array}{l}\text { Probability of inpatient } \\
\text { visit }\end{array}$ & The probability of seeking inpatient care. & 3.37 & 6.16 \\
\hline Hospitalization rate & Hospitalization rates in the year of 2003 or 2008. & 3.89 & 7.48 \\
\hline $\begin{array}{l}\text { Per-visit hospitalization } \\
\text { days }\end{array}$ & Mean per-visit hospitalization days. & 10.55 & 10.37 \\
\hline \multicolumn{4}{|l|}{ Independent variables } \\
\hline Income (RMB) & $\begin{array}{c}\text { Mean of per capita consumption expenditure. Natural log of income is introduced in regression } \\
\text { models. }\end{array}$ & 2690.32 & 4471.15 \\
\hline Female* & 1 if female, 0 otherwise. Omitted group. & 49.61 & 50.28 \\
\hline Male & 1 if male, 0 otherwise. & 50.39 & 49.72 \\
\hline Age $15-34^{*}$ & 1 if age between 15 and 34, 0 otherwise. Omitted group. & 37.52 & 30.96 \\
\hline Age $35-44$ & 1 if age between 35 and 44,0 otherwise. & 21.46 & 22.69 \\
\hline Age $45-54$ & 1 if age between 45 and 54,0 otherwise. & 19.74 & 19.19 \\
\hline Age $55-64$ & 1 if age between 55 and 64,0 otherwise. & 10.86 & 14.95 \\
\hline Age $65+$ & 1 if age between 65 and above, 0 otherwise. & 10.42 & 12.21 \\
\hline Not ill in last two weeks* & 1 if not ill in the last two weeks, 0 otherwise. Omitted group. & 85.12 & 21.62 \\
\hline Illness in last two weeks & 1 if ill in last two weeks, 0 otherwise. & 14.88 & 18.38 \\
\hline Not Chronic disease* & 1 if not chronic disease, 0otherwise. Omitted group & & \\
\hline Chronic disease & 1 if chronic disease, 0 otherwise. & 13.19 & 17.29 \\
\hline Sick days (day) & Sick days in last two weeks & 7.89 & 8.52 \\
\hline Bed days (day) & Days of staying in bed because of illness in last two weeks. & 1.30 & 1.16 \\
\hline Off-work days (day) & Days off work and study in last two weeks because of illness. & 1.80 & 1.43 \\
\hline Excellent health* & 1 if very good health, 0 otherwise. Omitted group. & 38.49 & - \\
\hline Good health & 1 if good health, 0 otherwise. & 36.34 & - \\
\hline Average health & 1 if health, 0 otherwise. & 19.99 & - \\
\hline Poor health & 1 if bad health, 0 otherwise. & 4.54 & - \\
\hline Very poor health & 1 if very bed health, 0 otherwise. & 0.65 & - \\
\hline Health status index & Mean scores of health status. & - & 80.66 \\
\hline Unmarried* & 1 if unmarried, 0 otherwise. Omitted group. & 18.37 & 16.52 \\
\hline Married & 1 if married, 0 otherwise. & 74.8 & 75.27 \\
\hline Divorced & 1 if divorced or separated, 0 otherwise. & 0.73 & 1.21 \\
\hline widowed & 1 if widowed, 0 otherwise. & 6.10 & 7.00 \\
\hline Illiterate* & 1 if illiterate, 0 otherwise. Omitted group. & 22.84 & 19.04 \\
\hline Elementary & 1 if graduating from elementary school, 0 otherwise. & 31.17 & 31.46 \\
\hline Primary & 1 if graduating from middle school, 0 otherwise. & 36.06 & 37.84 \\
\hline High & 1 if graduating from high school, 0 otherwise & 8.85 & 10.22 \\
\hline University & 1 if graduating from university, 0 otherwise & 1.09 & 1.45 \\
\hline Unemployment* & 1 if unemployment, 0 otherwise. Omitted group. & 3.95 & 12.92 \\
\hline farmer & 1 if farmer, 0 otherwise. & 72.28 & 64.39 \\
\hline student & 1 if student, 0 otherwise. & 6.31 & 7.17 \\
\hline Other occupations & 1 if other occupations, 0 otherwise. & 17.46 & 15.52 \\
\hline Eastern region* & 1 if eastern region, 0 otherwise. Omitted group. & 31.18 & 30.96 \\
\hline Central region & 1 if central region, 0 otherwise. & 26.84 & 27.42 \\
\hline Western region & 1 if western region, 0 otherwise. & 41.98 & 41.62 \\
\hline No medical insurance* & 1 if no medical insurance, 0 otherwise. Omitted group. & 87.49 & 6.51 \\
\hline CMS/NCMS & 1 if CMS or NCMS, 0 otherwise. & 9.67 & 90.24 \\
\hline Other medical insurance & 1 if other medical insurance, 0 otherwise. & 2.84 & 3.25 \\
\hline Time (minutes) & $\begin{array}{c}\text { Mean time of going to the nearest medical institution. Natural log of income is introduced in } \\
\text { regression models. }\end{array}$ & 14.26 & 13.75 \\
\hline Price of outpatient (RMB) & Median price of outpatient service. Natural log of outpatient price is introduced in regression models. & 39.08 & 72.03 \\
\hline Price of inpatient (RMB) & Median price of inpatient service. Natural log of inpatient price is introduced in regression models. & 1472.71 & 1976.60 \\
\hline
\end{tabular}


rates at $82.8 \%$ and $92.3 \%$ respectively. However, the pervisit hospitalization days decreased slightly, from 10.55 to 10.37 . Yet, from 2003 to 2008, rural residents' selfreported health status declined. For example, the probability of being ill in the last two weeks and the probability of having a chronic disease increased by $23.5 \%$ and $31.1 \%$. The coverage of health insurance for rural residents also underwent a substantial increase. In 2003, less than $13 \%$ residents were covered by health insurance, from which only $9.7 \%$ residents were covered by CMS; by 2008 , more than $90 \%$ residents were covered by NCMS. Compared with 2003, the average outpatient price and inpatient price increased by $84.3 \%$ and $34.2 \%$ in 2008, respectively. After deflating the per capita consumption expenditure in the year of 2008 to 2003 by using consumer price index, the per capita consumption expenditure in 2003 and 2008 were 2690 Yuan and 4471 Yuan respectively and the growth rate was $66.21 \%$.

\section{Income-related inequality and inequity}

The concentration indexes of the probability of an inpatient visit, number of inpatient visits and per-visit hospitalization days in 2003 and 2008 were positive and all of them were statistically significant at $5 \%$, which demonstrates that the rich are more likely to utilize inpatient services than the poor in Chinese rural areas. However, as the need of inpatient service has not been taken into account, inequality is not equivalent to inequity. The horizontal inequity indexes in health utilization were calculated by using the method of decomposition of the concentration index. As shown in table 2, all of the horizontal inequity indexes of probability of an inpatient visit, number of inpatient visits and per-visit hospitalization days in 2003 and 2008 were positive, which indicates that inpatient utilization inequities exist for rural residents in China, and that the rich utilize inpatient services more than the poor when they have the same health status (pro-rich inequity). Compared to the inequity of the probability of an inpatient visit, the inequity of number of inpatient visits was higher and both of them were higher than the inequity of pervisit hospitalization days. From 2003 to 2008, the horizontal inequity index of the probability of an inpatient visit and the number of inpatient visits decreased 48.37 and $43.59 \%$ respectively, while this index of per-visit hospitalization days increased $29.96 \%$.

\section{Decomposition of inequality}

After decomposing the concentration indexes of inpatient utilization, the income-related inequalities were decomposed into the contributions of different variables (as show in table 3 and table 4). The absolute value of contribution signifies the extant to which inequality can be attributed to this variable. The positive value of contribution means the variable contributes to pro-rich inequality, that is, the richer individuals use more inpatient service than the poor, and vice versa. As the variables were divided into four groups (income, need variables, other variables and residual term), the contribution of each variable-group was generated by adding up contributions of variables within each group (as show in Figure 1 and 2). The sum of the bars would be zero if utilization were equal across income and the need bar would be the only bar to appear if there were perfect equity.

Among these contributions, income made the greatest contribution to the inequality of inpatient utilization in each year and all of the contributions were positive, indicating that most of the pro-rich inequalities are accounted for by income. The contributions of need variables on the inequality of probability of an inpatient visit and the number of inpatient visits are negative in 2003 and 2008, meaning that poorer individuals have greater need, while the contributions on the inequality of pervisit hospitalization days are positive, suggesting that the wealthy have greater need of hospitalization. For the inpatient utilization in 2003 and 2008, the contributions of other variables on inequality were negative, of which inpatient price made the most contribution to the propoor inequality of the probability of an inpatient visit and inpatient visits (table 2). This is perhaps because the inequality of inpatient price is very small for rich and poor. The residual term made positive contributions on the inequality of all inpatient utilization in each year except the per-visit hospitalization days in 2003.

\section{Decomposition of change in the concentration index}

Table 1 shows that, from 2003 to 2008, the concentration indices of probability of an inpatient visit and the number of inpatient visits decreased by 48.79 and $44.49 \%$ respectively, meanwhile, the concentration index of per-visit hospitalization days increased by $16.47 \%$. In order to find out which factors resulted in the change of inequality,

Table 2 Concentration index and horizontal inequity index in inpatient utilization

\begin{tabular}{ccccccc}
\hline & \multicolumn{2}{c}{ Probability of inpatient visit } & \multicolumn{2}{c}{ Inpatient visits } & \multicolumn{2}{c}{ Per-visit hospitalization days } \\
\cline { 2 - 7 } & $\mathbf{C l}$ & $\mathrm{HI}$ & $\mathrm{Cl}$ & $\mathrm{HI}$ & $\mathrm{Cl}$ & $\mathrm{HI}$ \\
\hline 2003 & $0.2236^{*}$ & $0.2386^{*}$ & $0.2360^{*}$ & $0.2487^{*}$ & $0.0996^{*}$ & $0.0841^{*}$ \\
2008 & $0.1145^{*}$ & $0.1232^{*}$ & $0.1310^{*}$ & $0.1403^{*}$ & $0.1160^{*}$ & $0.1093^{*}$ \\
Change & -0.1091 & -0.1154 & -0.1050 & -0.1084 & 0.0164 & 0.0252 \\
\hline
\end{tabular}

Note: *significant at $5 \%$. 
Table 3 Decomposition of inequality in the inpatient utilization in 2003

\begin{tabular}{|c|c|c|c|c|c|c|}
\hline & \multicolumn{2}{|c|}{ Prob of inpatient visit } & \multicolumn{2}{|c|}{ Inpatient visits } & \multicolumn{2}{|c|}{ Per-visit hospitalization days } \\
\hline & Marginal effects & Contributions & Marginal effects & Contributions & Marginal effects & Contributions \\
\hline Income & $0.0178^{*}$ & 0.1972 & $0.0165^{*}$ & 0.1586 & $2.7567^{*}$ & 0.1022 \\
\hline Male & $-0.0061^{*}$ & 0.0006 & $-0.0041^{*}$ & 0.0003 & $2.4735^{*}$ & 0.0033 \\
\hline Age $35-44$ & $-0.0195^{*}$ & -0.0172 & $-0.0180^{*}$ & -0.0138 & $2.8649^{*}$ & 0.0054 \\
\hline Age $45-54$ & $-0.0173^{*}$ & 0.0025 & $-0.0156^{*}$ & 0.0020 & $3.9752^{*}$ & 0.0019 \\
\hline Age $55-64$ & $-0.0140^{*}$ & 0.0061 & $-0.0126^{*}$ & 0.0048 & $2.6040^{*}$ & -0.0009 \\
\hline Age $65+$ & $-0.0156^{*}$ & 0.0071 & $-0.0134^{*}$ & 0.0053 & $1.9663^{*}$ & 0.0000 \\
\hline Illness in last two weeks & 0.0000 & 0.0000 & 0.0004 & 0.0000 & $-1.8330^{*}$ & -0.0006 \\
\hline Chronic disease & $0.0378^{*}$ & 0.0025 & $0.0389^{*}$ & 0.0022 & $1.2519^{*}$ & 0.0015 \\
\hline Sick days & -0.0002 & 0.0001 & -0.0002 & 0.0000 & 0.0367 & 0.0005 \\
\hline Bed days & $0.0023^{*}$ & -0.0001 & $0.0017^{*}$ & -0.0001 & 0.0777 & 0.0003 \\
\hline Off-work days & $0.0009^{*}$ & -0.0001 & $0.0006^{*}$ & 0.0000 & $0.1085^{*}$ & 0.0006 \\
\hline Good health & $0.0026^{*}$ & -0.0005 & $0.0029^{*}$ & -0.0004 & 0.3327 & -0.0002 \\
\hline Average health & $0.0205^{*}$ & -0.0093 & $0.0192^{*}$ & -0.0076 & $1.9427^{*}$ & 0.0002 \\
\hline Poor health & $0.0513^{*}$ & -0.0060 & $0.0482^{*}$ & -0.0049 & $3.8084^{*}$ & 0.0030 \\
\hline Very poor health & $0.0760^{*}$ & -0.0007 & $0.0590^{*}$ & -0.0005 & $4.5021^{*}$ & 0.0014 \\
\hline Married & $0.0218^{*}$ & 0.0048 & $0.0211^{*}$ & 0.0041 & $-4.2129^{*}$ & -0.0031 \\
\hline Divorced & $0.0323^{*}$ & -0.0012 & $0.0264^{*}$ & -0.0009 & -1.9405 & 0.0005 \\
\hline widowed & $0.0366^{*}$ & -0.0078 & $0.0405^{*}$ & -0.0075 & $-2.7708^{*}$ & 0.0015 \\
\hline Elementary & $0.0055^{*}$ & -0.0033 & $0.0041^{*}$ & -0.0021 & -0.3005 & 0.0002 \\
\hline Primary & $0.0059^{*}$ & 0.0053 & $0.0037^{*}$ & 0.0029 & -0.6817 & -0.0012 \\
\hline High & $0.0079^{*}$ & 0.0063 & $0.0048^{*}$ & 0.0033 & -0.6855 & -0.0011 \\
\hline University & -0.0013 & -0.0002 & -0.0039 & -0.0006 & -0.5470 & -0.0003 \\
\hline farmer & 0.0028 & -0.0051 & 0.0026 & -0.0040 & $-1.4257^{*}$ & 0.0071 \\
\hline student & $-0.0069^{*}$ & -0.0029 & $-0.0054^{*}$ & -0.0020 & -1.2727 & -0.0006 \\
\hline Other occupations & -0.0028 & -0.0036 & -0.0026 & -0.0028 & -0.5469 & -0.0019 \\
\hline Central region & $-0.0024^{*}$ & 0.0003 & -0.0017 & 0.0002 & $2.5443^{*}$ & -0.0003 \\
\hline Western region & $0.0024^{*}$ & -0.0050 & 0.0021 & -0.0038 & $4.0404^{*}$ & -0.0330 \\
\hline CMS/NCMS & $-0.0036^{*}$ & -0.0014 & $-0.0024^{*}$ & -0.0008 & 0.7690 & 0.0017 \\
\hline Other medical insurance & $0.0085^{*}$ & 0.0029 & $0.0085^{*}$ & 0.0025 & $1.7101^{*}$ & 0.0028 \\
\hline Time & $0.0017^{*}$ & -0.0047 & $0.0022^{*}$ & -0.0052 & $0.8036^{*}$ & -0.0062 \\
\hline Price of outpatient & $0.0037^{*}$ & 0.0037 & $0.0038^{*}$ & 0.0033 & -0.4106 & -0.0010 \\
\hline Price of inpatient & $-0.0091^{*}$ & -0.0154 & $-0.0098^{*}$ & -0.0144 & $2.3316^{*}$ & 0.0196 \\
\hline LR Chi2 & 4510.55 & & 4566.26 & & 872.55 & \\
\hline$P$ & $<0.001$ & & $<0.001$ & & $<0.001$ & \\
\hline
\end{tabular}

Note: There are 112116 observations when decomposing the inequality of probability of inpatient visit and inpatient visits in 2003 , and 3742 observations when decomposing the Per-visit hospitalization days in 2003. Marginal effects which differ significantly from zero (at $p<0.05$ ) in the regressions are showed with *

the method of decomposing the change in concentration index was employed to analyze the contributions of each determinant on the change of inequality in inpatient utilization (table 5). Like each variable's contribution to inequality, the absolute value of the contribution to the change of inequality signifies to what extant the change can be attributed to each variable. The variable contributes to the increase of pro-rich inequality if the value of the contribution is positive, which means the gap of utilization between the rich and poor will increase, and vice versa.

From Figure 3, we found that, the variables of income, NCMS and inpatient price made great contributions to the change of inequality in inpatient utilization, from which income and NCMS contributed to the increase of pro-poor inequality and inpatient price contributed to the increase of pro-rich inequality. In addition, residual variables made big contributions to the increase of propoor inequality and other variables made little contributions to the change of inequality.

\section{Discussion}

Using the data from Chinese National Health Services Surveys (NHSS), this paper provided the first analysis of income-related inequality and inequity of inpatient utilization in rural China. The horizontal inequity index of 
Table 4 Decomposition of inequality in the inpatient utilization in 2008

\begin{tabular}{|c|c|c|c|c|c|c|}
\hline & \multicolumn{2}{|c|}{ Prob of inpatient visit } & \multicolumn{2}{|c|}{ Inpatient visits } & \multicolumn{2}{|c|}{ Per-visit hospitalization days } \\
\hline & Marginal effects & Contributions & Marginal effects & Contributions & Marginal effects & Contributions \\
\hline Income & $0.0244^{*}$ & 0.1462 & $0.0246^{*}$ & 0.1213 & $2.7223^{*}$ & 0.1013 \\
\hline Male & $-0.0125^{*}$ & 0.0003 & $-0.0095^{*}$ & 0.0002 & $3.2477^{*}$ & 0.0015 \\
\hline Age $35-44$ & $-0.0357^{*}$ & -0.0144 & $-0.0316^{*}$ & -0.0105 & $2.7352^{*}$ & 0.0045 \\
\hline Age $45-54$ & $-0.0320^{*}$ & 0.0025 & $-0.0282^{*}$ & 0.0018 & $3.0854^{*}$ & 0.0016 \\
\hline Age $55-64$ & $-0.0261^{*}$ & 0.0061 & $-0.0218^{*}$ & 0.0042 & $2.2320^{*}$ & -0.0026 \\
\hline Age $65+$ & $-0.0210^{*}$ & 0.0067 & $-0.0149^{*}$ & 0.0039 & $1.2718^{*}$ & -0.0014 \\
\hline Illness in last two weeks & -0.0024 & 0.0001 & -0.0009 & 0.0000 & $-2.3136^{*}$ & -0.0015 \\
\hline Chronic disease & $0.0591^{*}$ & -0.0001 & $0.0667^{*}$ & -0.0001 & $0.5897^{*}$ & -0.0001 \\
\hline Sick days & 0.0005 & -0.0002 & 0.0004 & -0.0001 & $0.1635^{*}$ & 0.0017 \\
\hline Bed days & $0.0036^{*}$ & 0.0002 & $0.0023^{*}$ & 0.0001 & $0.1303^{*}$ & 0.0014 \\
\hline Off-work days & $0.0020^{*}$ & 0.0003 & $0.0011^{*}$ & 0.0001 & -0.0650 & -0.0003 \\
\hline Health status index & $-0.0006^{*}$ & -0.0102 & $-0.0007^{*}$ & -0.0089 & $-0.0575^{*}$ & 0.0019 \\
\hline Married & $0.0393^{*}$ & 0.0047 & $0.0358^{*}$ & 0.0035 & $-4.6326^{*}$ & -0.0036 \\
\hline Divorced & $0.0544^{*}$ & -0.0007 & $0.0653^{*}$ & -0.0007 & -0.8367 & 0.0000 \\
\hline widowed & $0.0429^{*}$ & -0.0064 & $0.0347^{*}$ & -0.0043 & $-3.4078^{*}$ & 0.0029 \\
\hline Elementary & $0.0098^{*}$ & -0.0036 & $0.0090^{*}$ & -0.0027 & $-0.5663^{*}$ & 0.0008 \\
\hline Primary & $0.0112^{*}$ & 0.0053 & $0.0086^{*}$ & 0.0033 & $-1.1152^{*}$ & -0.0023 \\
\hline High & $0.0108^{*}$ & 0.0040 & $0.0088^{*}$ & 0.0027 & $-0.8167^{*}$ & -0.0011 \\
\hline University & 0.0129 & 0.0011 & 0.0126 & 0.0009 & -1.2779 & -0.0005 \\
\hline farmer & 0.0004 & -0.0004 & 0.0032 & -0.0024 & -0.3973 & 0.0021 \\
\hline student & $-0.0267^{*}$ & -0.0052 & $-0.0271^{*}$ & -0.0044 & $-1.7528^{*}$ & -0.0006 \\
\hline Other occupations & $-0.0061^{*}$ & -0.0054 & -0.0035 & -0.0025 & -0.3558 & -0.0015 \\
\hline Central region & $0.0113^{*}$ & -0.0003 & $0.0099^{*}$ & -0.0002 & $1.2769^{*}$ & 0.0005 \\
\hline Western region & $0.0097^{*}$ & -0.0127 & $0.0104^{*}$ & -0.0112 & $1.7177^{*}$ & -0.0121 \\
\hline NCMS & $0.0140^{*}$ & -0.0039 & $0.0146^{*}$ & -0.0033 & $1.7653^{*}$ & -0.0031 \\
\hline Other medical insurance & $0.0191^{*}$ & 0.0046 & $0.0220^{*}$ & 0.0044 & $5.5013^{*}$ & 0.0085 \\
\hline Time & 0.0000 & 0.0000 & -0.0002 & 0.0002 & $0.4640^{*}$ & -0.0032 \\
\hline Price of outpatient & 0.0016 & 0.0011 & 0.0009 & 0.0005 & $-0.5445^{*}$ & -0.0027 \\
\hline Price of inpatient & $-0.0202^{*}$ & -0.0255 & $-0.0212^{*}$ & -0.0221 & $0.9523^{*}$ & 0.0086 \\
\hline LR Chi2 & 5629.35 & & 5974.71 & & 1640.16 & \\
\hline$P$ & $<0.001$ & & $<0.001$ & & $<0.001$ & \\
\hline
\end{tabular}

Note: There are 103754 observations when decomposing the inequality of probability of inpatient visit and inpatient visits in 2008 , and 6373 observations when decomposing the Per-visit hospitalization days in 2008. Marginal effects which differ significantly from zero (at $p<0.05$ ) in the regressions are showed with *

inpatient service utilization in 2003 and 2008 shows that obvious pro-rich inequities of inpatient utilization exist in rural China, which indicates that a disproportionate share of inpatient resources are utilized by richer people in spite of lower need. These results are consistent with previous studies $[20,21]$. The results suggest, for instance, that the inequity of the number of inpatient visits is a little bit larger than the inequity of the probability of an initial inpatient visit. The inequity of the number of inpatient visits in rural China is therefore mainly generated by the initial inpatient visit rather than subsequent visits. Poorer individuals are far less likely to make an initial inpatient visit. However, those that make an initial visit are only slightly less likely than richer individuals to make subsequent visits. From 2003 to 2008, as the factors associated with inpatient utilization changed (e.g., income, inpatient price and coverage rate of medical insurance), the inequities of the probability of inpatient visit and inpatient visits decreased $48.27 \%$ and $43.59 \%$ respectively. This suggests that in spite of growing costs, improving income and greater health insurance coverage offset the increased price and have reduced income-related inequities in inpatient utilization. On the other hand, the inequity of per-visit hospitalization days increased by $29.96 \%$. There are two probable reasons for this increase in inequity. First, as the payment method is fee-for-service in hospitals, with the increase of price, poor individuals are more likely to shorten their number of hospitalization days compared with the rich even though the inpatient expenditure can be partly paid by health insurance. Second, although more than $90 \%$ of rural residents were enrolled in 


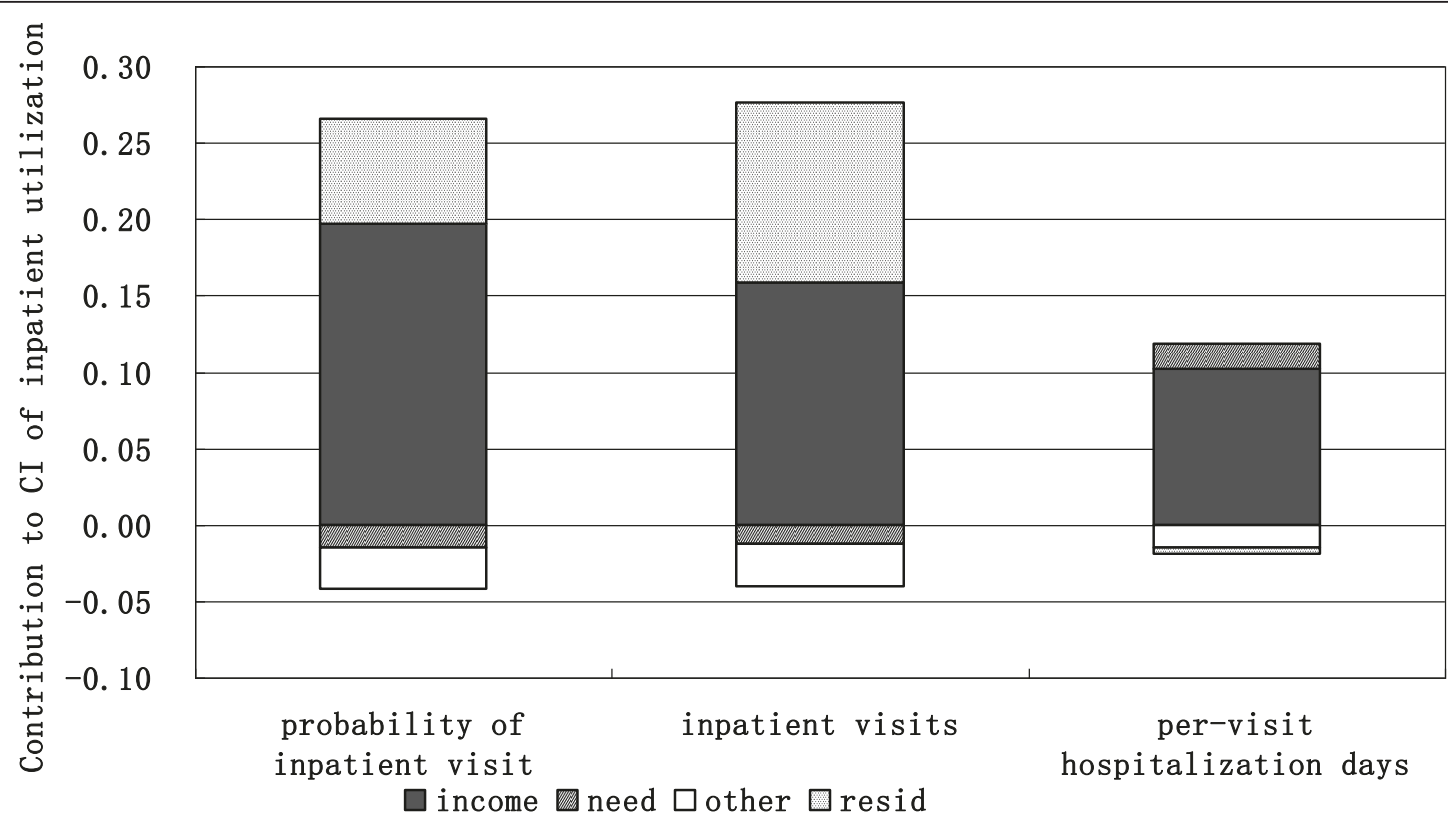

Figure 1 Decomposition of inequality in inpatient utilization in the year of 2003.

NCMS in 2008, the reimbursement rates of NCMS in primary hospitals are much higher than in high-level hospitals, but there are more average hospitalization days in high-level hospitals than in primary hospitals in China. As a result, poor enrollees are more likely to be hospitalized in primary hospitals in 2008 than in 2003 where they can get a higher reimbursement rate and richer individuals are more likely to be hospitalized in high-level hospitals where they will likely spend more days in the hospital. Consequently, poorer individuals will spend fewer days in the hospital than richer individuals even if their number of visits is the same.

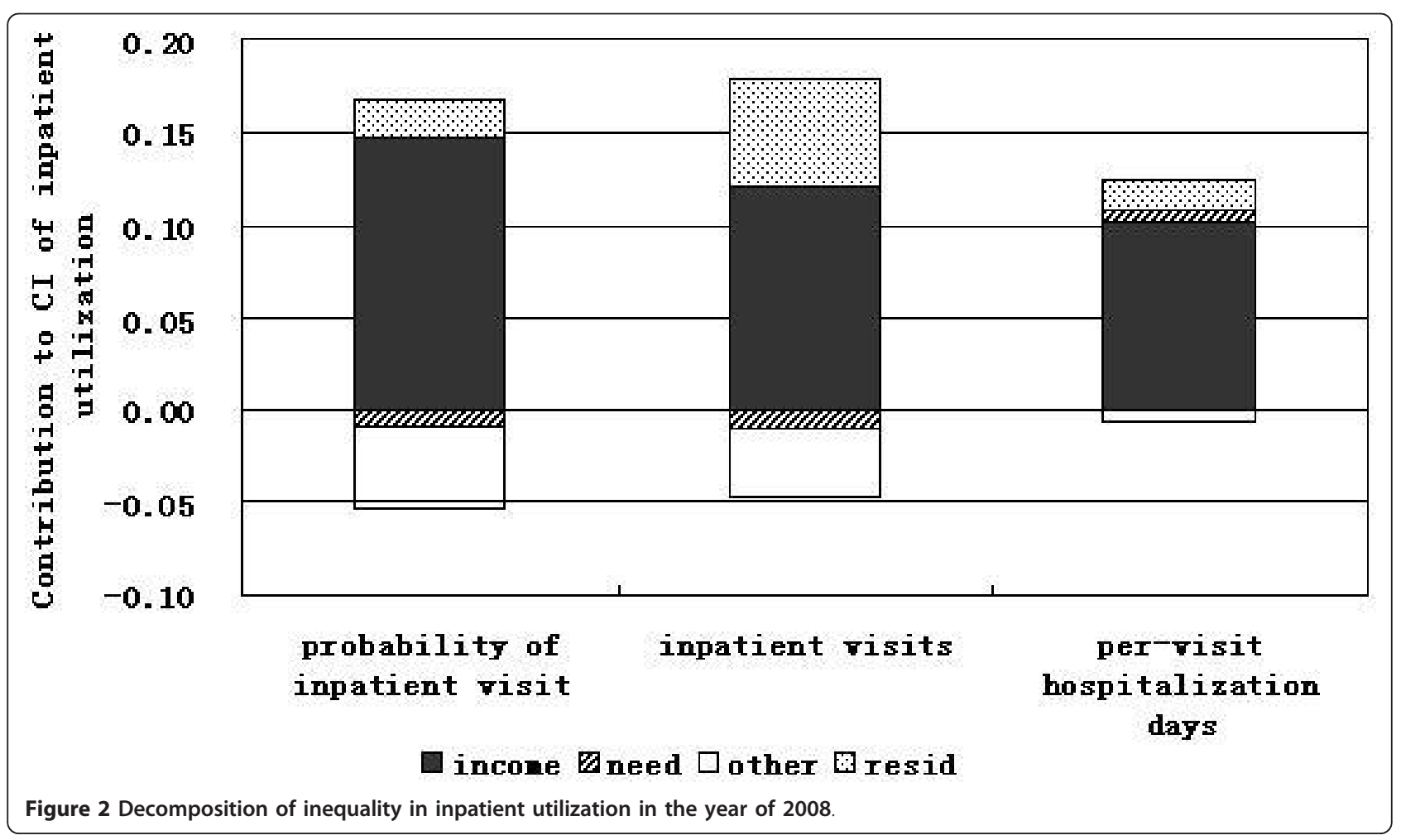


Table 5 Contributions of the change of inequality in inpatient utilization from the 2003 to 2008

\begin{tabular}{|c|c|c|c|}
\hline & Prob of inpatient visit & Inpatient visits & Per-visit hospitalization days \\
\hline Socioeconomic status & -0.0828 & -0.0952 & -0.0122 \\
\hline Male & 0.0054 & 0.0045 & -0.0058 \\
\hline Age $35-44$ & 0.0042 & 0.0038 & -0.0009 \\
\hline Age $45-54$ & 0.0060 & 0.0048 & 0.0020 \\
\hline Age $55-64$ & 0.0073 & 0.0052 & -0.0010 \\
\hline Age $65+$ & 0.0052 & 0.0021 & -0.0003 \\
\hline Illness in last two weeks & 0.0012 & 0.0006 & 0.0018 \\
\hline Chronic disease & -0.0150 & -0.0167 & 0.0024 \\
\hline Sick days & -0.0028 & -0.0022 & -0.0053 \\
\hline Bed days & -0.0002 & -0.0001 & 0.0010 \\
\hline Off-work days & 0.0004 & 0.0002 & -0.0002 \\
\hline Married & -0.0229 & -0.0183 & 0.0026 \\
\hline Divorced & -0.0003 & -0.0008 & -0.0004 \\
\hline widowed & -0.0040 & -0.0002 & 0.0031 \\
\hline Elementary & -0.0046 & -0.0045 & 0.0018 \\
\hline Primary & -0.0019 & -0.0018 & 0.0008 \\
\hline High & -0.0006 & -0.0003 & 0.0001 \\
\hline University & 0.0005 & 0.0005 & 0.0000 \\
\hline farmer & 0.0051 & -0.0006 & -0.0134 \\
\hline student & 0.0004 & 0.0006 & 0.0002 \\
\hline Other occupations & -0.0031 & -0.0010 & 0.0003 \\
\hline Central region & -0.0070 & -0.0056 & 0.0036 \\
\hline Western region & -0.0167 & -0.0163 & 0.0302 \\
\hline CMS/NCMS & -0.0586 & -0.0560 & -0.0456 \\
\hline Other medical insurance & 0.0028 & 0.0027 & 0.0039 \\
\hline Time & 0.0095 & 0.0123 & 0.0118 \\
\hline Price of outpatient & 0.0130 & 0.0183 & 0.0076 \\
\hline Price of inpatient & 0.1431 & 0.1410 & 0.0993 \\
\hline
\end{tabular}

After decomposing the inequality of inpatient utilization, we find that income made the greatest pro-rich contribution to the inequality of inpatient utilization. In other words, rising incomes between 2003 and 2008 increased income differentials in utilization rates. As previously noted, the contribution of income is equal to the product of the elasticity of inpatient utilization and the inequality of residents' income (measured as the income Gini coefficient). Because we cannot change the elasticity of inpatient price, the only effective way to increase the equity of inpatient utilization is to reduce the inequality of residents' income. As table 6 demonstrates, the income Gini coefficient was larger in 2003 than in 2008 (0.369 and 0.363 respectively), which is consistent with the fact that the inequities in the probability of an inpatient visit and number of inpatient visits in 2003 is greater than 2008. The contributions of need variables to the inequality of inpatient utilization are similar in 2003 and 2008. In both years, the contributions to the probability of an inpatient visit and number of inpatient visits are in a propoor direction and the contribution to per-visit hospitalization days is in a pro-rich direction. This indicates that the poor need relatively more inpatient utilization, but that rich individuals likely need more per-visit hospitalization days than the poor. A potential explanation for this finding is that poor rural individuals are more likely to suffer from diseases that require more inpatient visits than rich individuals, but rich individuals suffer more from chronic disease that requires longer term care than poor individuals (i.e., rich individuals are more likely to develop chronic diseases, such as hypertension, diabetes and coronary heart disease, than poor individuals in rural China). Thus, need has stayed relatively constant even as inequity has reduced.

Theoretically, the contribution of each determinant to the change of concentration index of inpatient utilization can be attributed to an interaction of changes, which includes the change of this determinant, the change of the determinant' concentration index, and the change of partial effects of the determinant on inpatient utilization. The results show that the main determinants of the change are improving income, NCMS and inpatient price. Therefore, the increase in income, the decrease in pro-rich inequality of income, the improvement of the 


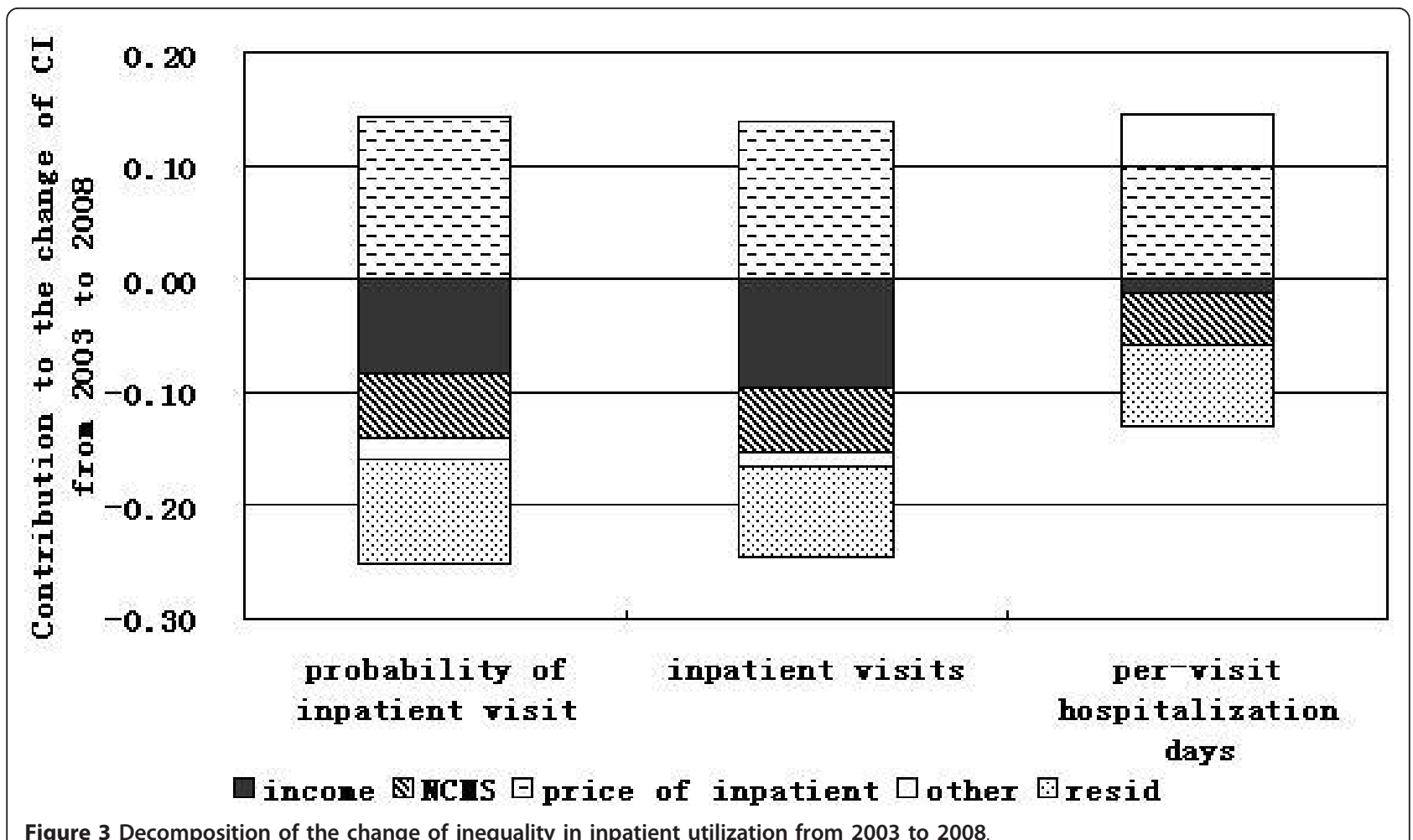

coverage rate of NCMS and the decrease in pro-rich inequality of NCMS made a great contribution to reduce the pro-rich inequality from 2003 to 2008 . Meanwhile, the increase in inpatient price and the pro-rich inequality of inpatient price made a great contribution to increase the pro-rich inequality (see table 6). Furthermore, the results also show that residual variables contributed a lot to the increase in pro-poor inequality, suggesting that there remains a good deal of unexplained variation in changes in inequity beyond the variables examined in this analysis.

There are several limitations to this study which should be noted. Firstly, health status, which is used to measure health care need, is self-reported. Self-reported health status can be considerably affected by residents' health consciousness level and health knowledge level. For instance, poor people's self-reported health status may better than their actual health status because they

Table 6 Description of main determinants and their concentration indexes in 2003 and 2008

\begin{tabular}{lcccc}
\hline & \multicolumn{2}{c}{2003} & \multicolumn{2}{c}{2008} \\
\cline { 2 - 5 } & Means & $\mathrm{Cl}$ & Means & $\mathrm{Cl}$ \\
\hline Income (RMB) & 2690 & $0.369^{*}$ & 4471 & $0.363^{*}$ \\
CMS/NCMS (\%) & 9.67 & -0.016 & 90.24 & -0.019 \\
Inpatient price (RMB) & 1473 & 0.008 & 1977 & 0.010 \\
\hline
\end{tabular}

Note: ${ }^{*}$ Gini coefficient is based on income. lack health consciousness and knowledge to make accurate assessments compared with wealthier individuals. Therefore, the equity of inpatient utilization may be underestimated in this paper. Secondly, due to the impossibility of attaining actual medical prices in each region, we assumed that the medical prices are identical in the county level, and measured outpatient price and inpatient price by the medians of per-visit outpatient expenses and inpatient expenses in each county. The rationale for this assumption should be further validated.

\section{Conclusion}

There is a strong pro-rich inequity of inpatient utilization in Chinese rural areas. The horizontal equity of both the probability of initial inpatient visit and total number of visits greatly improved from 2003 to 2008, compared with a decline in the horizontal equity of per-visit hospitalization days. As income was the main factor contributing to the pro-rich inequality of inpatient utilization, this study suggests that an effective way to reduce the inequity is to narrow the gap of income between the rich and poor. As income, NCMS and the inpatient price were highly associated with the change of inequality in inpatient utilization from 2003 to 2008, improved income, a narrowed gap of income between the rich and the poor and an increased coverage rate of NCMS (especially for poor individuals) have effectively facilitated the improvement of equity in inpatient utilization. Meanwhile, the increased inpatient 
price and its increased inequality in rural China have hindered the improvement of the equity in inpatient utilization.

\section{Acknowledgements}

The authors would like to thank Shenglan Tang, Henry Lucas and Shaokang Zhan for their contributions to design of the study. The authors also want to thank China Medical Board of New York Inc. (CMB) and Center for Health Statistics and Information of Chinese Health Ministry (CHSI) for financial support. This work was also supported by Ministry of Education of China (Serial number: 08JZD0022).

\section{Author details}

${ }^{1}$ School of Public Policy and Administration, Xi'an Jiaotong University, Xi'an, China. ${ }^{2}$ Division of Health Policy and Administration, Yale School of Public Health, Yale University, New Haven, CT, USA. ${ }^{3}$ Centre of Health Statistics and Information, Ministry of Health, Beijing, China. ${ }^{4}$ World Health Organization, Geneva, Switzerland.

\section{Authors' contributions}

ZZ participated in the design, data analysis and was the primary person responsible for drafting the manuscript. JG participated in the design, data analyses and review. AF participated in writing, review and revision. KR participated in the design, data collection and data analysis. KX participated in the design and review. LX and $Y Z$ participated in the data collection and review. All authors read and approved the final manuscript.

\section{Competing interests}

The authors declare that they have no competing interests.

Received: 27 September 2010 Accepted: 21 August 2011 Published: 21 August 2011

\section{References}

1. Gao J, Gao J, Tang S, Tolhurst R, Rao K: Changing access to health services in urban China: implications for equity. Health Policy Plan 2001, 16(3):302-312

2. Luo J, Zhang $X$, Jin C, Wang D: Inequality of access to health care among the urban elderly in northwestern China. Health Policy 2009, 93(23):111-117.

3. Fang $P$, Dong S, Xiao J, Liu C, Feng X, Wang Y: Regional inequality in health and its determinants: evidence from China. Health Policy 2010, 94(1):14-25.

4. Van Doorslaer E, Koolmana X, Jones AM: Explaining Income-related Inequalities in Doctor Utilization in Europe. Health Economics 2004, 13:629-647.

5. Wagstaff A, Van Doorslaer E: Measuring and Testing for Inequity in the Delivery of Health Care. Journal of Human Resources 2000, 35(4):716-733.

6. Wagstaff A, van Doorslaer E, Paci P: On the measurement of horizontal inequity in the delivery of health care. Journal of Health Economics 1991, 10(2):169-205.

7. Mooney G: And now for vertical equity? Some concerns arising from aboriginal health in Australia. Health Economics 1996, 5(2):99-103.

8. National Bureau of Statistics of China: Statistical Bulletin of National Economy and Social Development in 2009. [http://www.stats.gov.cn/tjgb/ ndtjgb/qgndtjgb/t20100225_402622945.htm].

9. Center for Health Statistics and Information of $\mathrm{MOH}$ : An Analysis Report of National Health Services Survey in 2008. Xie He Medical University Press: Beijing; 2009.

10. Gao J, Zhou Z, Yan J, Yang X: Empirical Study on Chinese Health Care Access in Basic Health Insurance System. Chinese Health Economics 2010 27(7):5-8.

11. Zhou Z, Gao J, Yang X: Study on Equity in Health Service Delivery of Western Rural Residents. Chinese Health Economics 2010, 29(9):88-90.

12. World Health Organization representative in China and the Development Research Center of State Council: China: health, poverty and economic development. Beijing; 2006.
13. Tang X, Zhang J: Analysis on the Utilization and Influence Factors of the Outpatient Service of Rural Residents in Four Counties. Modern Preventive Medicine 2009, , 7: 1255-1257.

14. National Bureau of Statistics of China: Statistical Bulletin of National Economy and Social Development in 2000. 2001 [http://www.stats.gov.cn/ tjgb/ndtjgb/qgndtjgb/t20020331_15395.htm].

15. Center for Health Statistics and Information of $\mathrm{MOH}$ : Statistical Bulletin of Chinese Health Development in 2000. 2001 [http://www.100md.com/ Html/Dir0/10/93/02.htm].

16. Center for Health Statistics and Information of $\mathrm{MOH}$ : Statistical Bulletin of Chinese Health Development in 2009. 2010 [http://www.moh.gov.cn/ publicfiles/business/htmlfiles/zwgkzt/pgb/201006/47783.htm].

17. Shang L: Discussion on Chinese rural health insurance: talk about Chinese rural health insurance from the phenomena of "poverty due to illness". Journal of Chendu College of Education 2004, 18(12):73-75.

18. Zhao Y, Zhang Y, Tang J, Wang L, Wan Q, Tou S: Case Study on Horizontal Equity in Health Services Utilization is a component of Equity Research in Health Areas. Chinese Health Economics 2005, 7: 5-7.

19. Gao J, Zhou Z: Evaluation on Effect of Rural Mutual Health Care Improving Health Service Fairness. Chinses Health Economics 2007, 26(10):39-42.

20. Li X, Dong L, Wang J, Luo J, He L, Yu J, Meng Q: Analysis of Equity on Health Care Services Utilization in Three Pilot Counties of the New Rural Cooperative Medical System in Yunnan. Chinese Health Economics 2008, 11: $44-46$

21. Li X: Examining the Equity of Rural New Cooperative Medical and Health System: Health Level, Services Utilization and Fundraising. Chinese Journal of Population Science 2009, , 3: 96-102.

22. Kakwani NC, Wagstaff A, van Doorslaer E: Socioeconomic Inequalities in Health: Measurement, Computation and Statistical Inference. Journal of Econometrics 1997, 77(1):87-104.

23. Wagstaff A, van Doorslaer E, Paci P: Equity in the Finance and Delivery of Health Care: Some Tentative Cross-Country Comparisons. Oxford Review of Economic Policy 1989, 5(1):89-112.

24. Wagstaff A, Paci P, van Doorslaer E: On the Measurement of Inequalities in Health. Social Science \& Medicine 1991, 33:545-557.

25. Jenkins S: Calculating Income Distribution Indices from Microdata. National Tax Journal 1988, 61:139-142.

26. Wagstaff A, van Doorslaer E, Watanabe N: On Decomposing the Causes of Health Sector Inequalities, with an Application to Malnutrition Inequalities in Vietnam. Journal of Econometrics 2003, 112(1):219-227.

27. Wang H, Zhang L, Hsiao W: III Health and Its Potential Influence on Household Consumptions in Rural China. Health Policy 2006, 78:167-177.

28. Meyer BD, Sullivan JX: Measuring the Well-Being of the Poor Using Income and Consumption. Journal of Human Resources 2003, v38:1180-1220.

29. Culyer AJ: Need: The Idea Won't Do-But We Still Need It. Social Science \& Medicine 1995, 40(6):727-730.

30. Culyer AJ, Wagstaff A: Equity and Equality in Health and Health Care. Journal of Health Economics 1993, 12(4):431-57.

\section{Pre-publication history}

The pre-publication history for this paper can be accessed here: http://www.biomedcentral.com/1472-6963/11/201/prepub

doi:10.1186/1472-6963-11-201

Cite this article as: Zhou et al.: Measuring the equity of inpatient utilization in Chinese rural areas. BMC Health Services Research 2011 11:201. 